Герпетологические исследования проводились в Кафском биосферном заповеднике (Эфиопия, провинция Каффа) в период 2014-2015 гг. Нами найдено 16 видов земноводных, относящихся к семи семействам (19 видов, включая литературные данные). Из них - один вид новый для науки (Leptopelis sp.), четыре вида, известные по единичным находкам в Эфиопии (Afrixalus clarkei, Afrixalus enseticola, Hyperolius kivuensis, Phrynobatrachus inexpectatus), и семь видов, новые для фауны заповедника (Hyperolius kivuensis, Hyperolius nasutus, Hyperolius viridiflavus, Leptopelis ragazzii, Leptopelis sp., Ptychadena erlangeri, Phrynobatrachus inexpectatus). Уровень эндемизма среди Anura в Эфиопии очень высок. Из обитающих на территории заповедника 32 \% видов - эндемики гор юго-западной Эфиопии. Библиогр. 8 назв. Ил. 1. Табл. 1.

Ключевые слова: земноводные, Кафский биосферный заповедник, Эфиопия, эндемизм.

\author{
K. D. Milto ${ }^{1}$, M. V.Pestov ${ }^{2}$, T. Kirschey ${ }^{3}$
}

\title{
PRELIMINARY DATA ON THE BATRACHOFAUNA OF THE KAFFA BIOSPHERE RESERVE
}

${ }^{1}$ Zoological Institute RAS, 1, Universitetskaya nab., St. Petersburg, 199034, Russian Federation; coluber@zin.ru

2 Society of Amphibians and Reptiles Conservation, 16, Rozhdestvenskaya ul., Nizhny Novgorod, 603001, Russian Federation; vipera@dront.ru

${ }^{3}$ NABU Headquarters, 3, Charitéstrasse, Berlin, 10117, Germany; tom.kirschey@nabu.de

Herpetological field research in the Kaffa Biosphere Reserve (Ethiopia, Kaffa) was carried out in 20142015. We recorded 16 species of amphibians from 7 families (19 species from 9 families including previously reported). The list includes 1 new species (Leptopelis sp.), 4 species known by single findings in Ethiopia (Afrixalus clarkei, A.enseticola, Hyperolius kivuensis, Phrynobatrachus inexpectatus) and 7 species first reported for Kaffa Biosphere Reserve (H. kivuensis, H. nasutus, H. viridiflavus, L. ragazzii, Leptopelis sp., Ptychadena erlangeri, Phrynobatrachus inexpectatus). The level of endemism among anurans in Ethiopia is very high. Of the species listed for Kaffa Biosphere Reserve, $32 \%$ are endemic to the mountains of Southwestern Ethiopia. Refs 8. Figs 1. Tables 1.

Keywords: amphibians, Kaffa Biosphere Reserve, Ethiopia, endemism.

\section{Введение}

Кафский биосферный заповедник (Kaffa Biosphere Reserve) располагается в юго-западной Эфиопии, в области народностей Южной Эфиопии, в провинции Каффа. Провинция Каффа лежит на окраине Эфиопского плато преимущественно в зоне саванн, а также листопадных и вечнозелёных лесов. Климат Эфиопии относится к типу экваториально-муссонного. Субэкваториальные черты климата проявляются в преобладании высоких температур в течение года. В горах амплитуда суточных и сезонных колебаний температур довольно велика. В горах, где увеличиваются облачность и осадки, температуры (особенно дневные) ниже в дождливый

К.Д.Мильто (coluber@zin.ru): Зоологический институт РАН, Российская Федерация, 199034, Санкт-Петербург, Университетская наб., 1; М.В.Пестов (vipera@dront.ru): Общество охраны амфибий и рептилий при экоцентре «Дронт», Российская Федерация, 603001, Нижний Новгород, ул. Рождественская, 16-Д; Т. Киршей (tom.kirschey@nabu.de): NABU Headquarters, Германия, 10117, Берлин, Чартештрассе, 3.

() Санкт-Петербургский государственный университет, 2016 
сезон. Наиболее холодный месяц - июль, самый жаркий - декабрь или январь, т. е. годовой ход температуры сходен с режимом южного полушария.

Обширная территория Сомалийско-Эфиопского нагорья занята преимущественно саваннами, Афарская впадина - пустыней. Для западной оконечности Эфиопского нагорья характерны листопадные редколесья (босвеллия, акации, терминалия, коммифора). И только на юго-западе Эфиопии, в условиях сочетания обильных осадков и высоких температур, имеются крупные массивы влажных тропических лесов, расположенных в большом высотном диапазоне высот - от 500 до 3300 м над уровнем моря. Наиболее выраженные сомкнутые вечнозеленые леса сформированы на юго-западе, на небольших высотах, где годовой уровень осадков достигает 1500 мм. С высоты 1800 до 3300 м распространены листопадные и частично листопадные леса с доминированием Juniperus или Aningeria, Hagenia, Hypericum $[1,2]$. Фаунистическое разнообразие и уровень эндемизма, как считается [3], здесь ниже, чем в тропических лесах Западной Африки, что связывают с недавним окончанием формирования местных лесов (8 тыс. лет назад). Тем не менее именно из юго-западного нагорья описан ряд эндемичных видов амфибий и рептилий.

Территория Кафского заповедника лежит в зоне горных вечнозеленых лесов, также представлены горные луга и водно-болотные угодья по долинам рек и на равнине. Диапазон высот от 500 до 3300 м над уровнем моря. Заповедник занимает площадь 747008 га, включая буферную и переходную зоны. Переходная зона активно эксплуатируется, леса сильно вырублены, территория заселена.

Полевые работы мы проводили преимущественно в центральной части заповедника с базой в поселке Бонга в ноябре-декабре 2014 и феврале-марте 2015 г. Нами были обследованы следующие участки леса и пойменных участков в диапазоне высот 1300-2000 м над уровнем моря:

1) окрестности Бонги, включающие нагорные вечнозеленые леса на склонах, разной степени сохранности, долину реки в антропогенном ландшафте и окружающие плантации и водопад на реке Барта, $1832-1925$ м над уровнем моря $\left(7,25090^{\circ} \mathrm{N}\right.$, $\left.36,25483^{\circ} \mathrm{E}\right)$;

2) окрестности деревни Бока, лес Бока и ручей в низменности, 2414 м над уровнем моря $\left(7,29467^{\circ} \mathrm{N}, 36,37604^{\circ} \mathrm{E}\right)$;

3) бамбуковая роща в лесу Бонга, 2595-2650 м над уровнем моря $\left(7,24118^{\circ} \mathrm{N}\right.$, $\left.36,45182^{\circ} \mathrm{E}\right)$

4) пойменный лес в долине реки Гумми, 1293 м над уровнем моря $\left(7,09281^{\circ} \mathrm{N}\right.$, $\left.36,23154^{\circ} \mathrm{E}\right)$;

5) низменность в окрестностях деревни Шорири, 1626 м над уровнем моря $\left(7,35707^{\circ} \mathrm{N}, 36,20437^{\circ} \mathrm{E}\right)$;

6) первичный лес и участки вторичной растительности в окрестностях деревень Вушвуш и Комба, 1847-1900 м над уровнем моря $\left(7,30803^{\circ} \mathrm{N}, 36,12201^{\circ} \mathrm{E}\right)$;

7) низменность в долине реки Алемгоно, между поселками Бонга и Гимбо, 1706 м над уровнем моря $\left(7,34891^{\circ} \mathrm{N} ; 36,24099^{\circ} \mathrm{E}\right)$;

8) лес Манкира, расположенный между поселками Манкира и Эндерах, 1550 м над уровнем моря $\left(7,17968^{\circ} \mathrm{N} ; 36,26752^{\circ} \mathrm{E}\right)$;

9) низменность в долине реки Годжеб, между поселками Богинда и Медабо, $1516-1630$ м над уровнем моря $\left(7,55552^{\circ} \mathrm{N} ; 36,05157^{\circ} \mathrm{E}\right)$; 
10) лес и пастбища у поселка Богинда, 2074 м над уровнем моря $\left(7,50175^{\circ} \mathrm{N}\right.$, $\left.36,09118^{\circ} \mathrm{E}\right)$.

\section{Результаты}

В результате полевых исследований на территории Кафского заповедника нами были найдены 16 видов земноводных, представленных семью семействами.

1. Семейство Pyхicephalidae

Afrana angolensis (Bocage, 1866) - афротропический вид, очень обычный у рек и ручьев в лесной зоне. Отмечена в пойме Алемгоно, на реке Барта и в лесу Манкира.

2. Семейство Ptychadenidae

Ptychadena erlangeri (Ahl, 1924) - один из двух видов горных птихаден, распространенных в регионе Каффа [2, 4], эндемик Эфиопии. Населяет склоны Рифтовой долины на высотах 1300-2500 м. В заповеднике очень обычна, является фоновым видом. Отмечена в долине реки Алемгоно; на вырубке у деревни Вушвуш и в долине реки Годжеб.

Ptychadena neumanni (Ahl, 1924) - эндемик Эфиопского плато, представлен комплексом видов, в регионе Каффа встречается P. neumanni s.str. [4]. Фоновый вид амфибий. Отмечена на пастбищах в Бонге, на реке Барта; в лесу Манкира у деревни Эндерах.

3. Семейство Conrauidae

Conraua beccarii (Boulenger, 1911) - эндемик Эфиопского плато, постоянно-водный обитатель быстрых рек и горных ручьев, в районе исследований обычен. Отмечен в реке в Бонге; у водопада в реке Барта; в Комба и бамбуковом лесу Бонга; в реке у «God's Bridge» и в лесу Манкира.

4. Семейство Phrynobatrachidae

Phrynobatrachus inexpectatus Largen, 2001 - эндемик гор юго-западной Эфиопии. Найден в маленьком болотце с маршанцией в низменности у деревни Бока. В месте находки - многочисленнен. Это третья находка для вида, лежащая на 100 км северо-западнее известных ранее.

Phrynobatrachus minutus Boulenger, 1895 - эндемик Эфиопского плато, населяющий горные леса в диапазоне высот 800-2800 м. Доминирующий вид амфибий в лесной части, заболоченных низменностях и на лугах в большинстве исследованных биотопов. В районе Бока симпатричен с Phr. inexpectatus. Отмечен также в долине Алемгоно и в Шорири.

Phrynobatrachus natalensis (Smith, 1849) - широко распространенный вид в саванных регионах тропической Африки. В заповеднике - массовый вид. Отмечен в долинах рек Алемгоно и Годжеб.

5. Семейство Hyperoliidae

Afrixalus clarkei Largen, 1974 - узкоареальный эндемик гор юго-западной Эфиопии, где был ранее известен из трех локалитетов. Найден нами на кустарниковой растительности в лесу Бока и в долине Шорири, а также на краю пойменного леса в долине реки Годжеб.

Afrixalus enseticola Largen, 1974 - эндемик горных лесов Эфиопии, в заповеднике обычен. Отмечен в речных долинах в районе Алемгоно, Бока, Шорири, реки 
Годжеб и у водопада на реке Барта в окрестностях Бонги, откуда и был ранее описан.

Hyperolius kivuensis Ahl, 1931 - афротропический вид, в Эфиопии редок, спорадически распростанен в юго-западной части страны. Отмечен в долине реки Годжеб, это первая находка вида в регионе и третья для Эфиопии.

Hyperolius nasutus Günther, 1865 - широко распространенный южно-африканский вид. Обычен на территории заповедника. Найден в долинах Алемгоно и Годжеб и в других местах. В первых числах марта отмечена массовая миграция молоди после метаморфоза.

Hyperolius viridiflavus (Duméril and Bibron, 1841) - широко распространенный в Центральной и Восточной Африке вид. На территории заповедника обычен, отмечен почти повсеместно.

6. Семейство Arthroleptidae

Leptopelis ragazzii (Boulenger, 1896) - вид горных лесов Эфиопии (1900-3100 м) по обе стороны Рифтовой Долины, эндемик центрального плато Эфиопии. В горной части заповедника - обычен. В отличие от близкого L. vannutelli, всегда представлен двумя цветовыми морфами [5]. Токующие особи отмечены в водопаде на реке Барта, в самой реке, в лесу Манкира.

Leptopelis vannutellii (Boulenger, 1898) - населяет горные леса Эфиопии (15002200 м), эндемик юго-западной Эфиопии. Морфологически сходен с L. ragazzii, голоса обоих видов практически идентичны [5]. По нашим наблюдениям отличается окраской и местообитаниями (кроны деревьев). Отмечен в поселке Бонга.

Leptopelis sp. - новый для фауны представитель Arthroleptidae, найден в водноболотных угодьях в лесу Бока в декабре 2014 г. Предположительно отнесен к роду Leptopelis. Имеет очень характерный кожный орнамент и окраску, не позволяющие отнести его ни к одному из известных представителей данного семейства в Восточной Африке. По-видимому, эндемик горных лесов юго-западной Эфиопии.

7. Семейство Pipidae

Xenopus clivii Peracca, 1898 - восточно-африканский вид, распространенный в Эфиопии, Эритрее, Танзании и Судане. Отмечены в долине Алемгоно и в реке Барта. Это вторая находка вида в юго-западной Эфиопии.

Помимо перечисленных видов для территории заповедника также ранее был указан Hemisus microscaphus Laurent, 1972 [2, 6]. Указанные Kassina senegalensis и Hoplobatrachus occipitalis [6, 7] нами также отмечены не были, но присутствие этих видов в заповеднике очень вероятно. Напротив, Bufo dodsoni, Bufo garmani и Ptychadena pumilio указаны в списке видов заповедника явно по ошибке [7]. Оба вида жаб - Bufo dodsoni, населяющая пустынную зону Афарской низменности, и Bufo garmani, населяющая саванны юго-восточной Эфиопии, в юго-западной Эфиопии не обитают и в зоне горных лесов встречены быть не могут. Западноафриканская Ptychadena pumilio, известная по трем находкам из западной Эфиопии, на территории заповедника также, скорее всего, не встречается.

Таким образом, на территории Кафского заповедника на сегодняшний день, включая наши данные, зарегистрировано 19 видов бесхвостых земноводных. Нами найдены 16 видов, представленных семью семействами. Из них один вид - новый для науки (Leptopelis sp.), четыре вида, известные по единичным находкам в Эфиопии (Afrixalus clarkei, Afrixalus enseticola, Hyperolius kivuensis, Phrynobatrachus 
Списки видов Anura Кафского Биосферного заповедника

\begin{tabular}{|c|c|c|}
\hline «Wildlife species in Bonga» & Largen and Spawls (2010) & Наши данные, 2014-2015 \\
\hline Bufo garmani & - & - \\
\hline Bufo dodsoni & - & - \\
\hline- & Hemisus microscaphus & - \\
\hline- & - & - \\
\hline- & Afrixalus clarkei & Afrixalus clarkei \\
\hline - & Afrixalus enseticola & Afrixalus enseticola \\
\hline- & - & Hyperolius kivuensis \\
\hline- & - & Hyperolius nasutus \\
\hline- & - & Hyperolius viridiflavus \\
\hline Kassina senegalensis & - & - \\
\hline- & - & Leptopelis ragazzii \\
\hline- & Leptopelis vannutellii & Leptopelis vannutellii \\
\hline- & - & Leptopelis sp. \\
\hline - & Afrana angolensis & Afrana angolensis \\
\hline- & Conraua beccarii & Conraua beccarii \\
\hline Hoplobatrachus occipitalis & - & - \\
\hline- & - & Ptychadena erlangeri \\
\hline- & Ptychadena neumanni & Ptychadena neumanni \\
\hline Ptychadena pumilio & - & - \\
\hline- & - & Phrynobatrachus inexpectatus \\
\hline Phrynobatrachus minutus & Phrynobatrachus minutus & Phrynobatrachus minutus \\
\hline- & Phrynobatrachus natalensis & Phrynobatrachus natalensis \\
\hline Xenopus clivii & - & Xenopus clivii \\
\hline 7 видов, 6 семейств & 9 видов, 7 семейств & 16 видов, 7 семейств \\
\hline
\end{tabular}

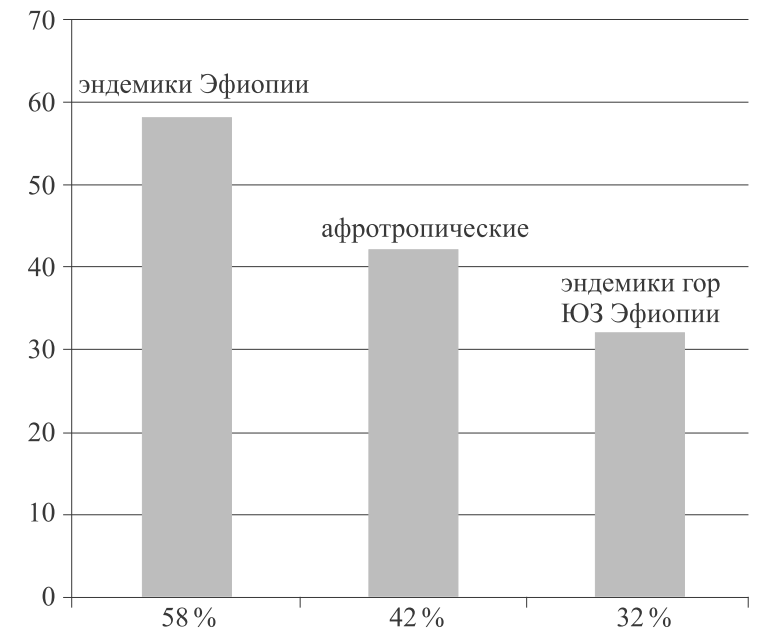

Биогеографические группы видов Anura в фауне Кафского Биосферного завповедника 
inexpectatus), и семь видов - новые для фауны заповедника (Hyperolius kivuensis, Hyperolius nasutus, Hyperolius viridiflavus, Leptopelis ragazzii, Leptopelis sp., Ptychadena erlangeri, Phrynobatrachus inexpectatus). Сравнить динамику изученности бесхвостых амфибий можно по таблице.

В заповеднике представлены как эндемики Эфиопского плато, так и эндемики гор юго-западной Эфиопии (рисунок). Эндемики Эфиопии представлены в заповеднике 11 видами (Hemisus microscaphus, Afrixalus clarkei, Afrixalus enseticola, Leptopelis ragazzii, Leptopelis vannutellii, Leptopelis sp., Conraua beccarii, Phrynobatrachus inexpectatus, Phrynobatrachus minutus, Ptychadena erlangeri, Ptychadena neumanni), из них 6 видов - эндемики гор юго-западной Эфиопии (Hemisus microscaphus, Afrixalus clarkei, Afrixalus enseticola, Leptopelis vannutellii, Leptopelis sp., Phrynobatrachus inexpectatus). Остальные 8 видов широко распространены в тропической Африке (Afrana angolensis, Phrynobatrachus natalensis, Hoplobatrachus occipitalis, Hyperolius kivuensis, Hyperolius nasutus, Hyperolius viridiflavus, Kassina senegalensis, Xenopus clivii).

Можно прогнозировать значительное расширение видового списка при дальнейшем изучении территории за счет равнинных и низкогорных видов в западной части заповедника и описания новых, эндемичных видов гор юго-западной Эфиопии. Уровень эндемизма среди Anura в горном регионе Каффа оказался очень высок и составляет на сегодняшний день $32 \%$. Высокий уровень видового эндемизма у амфибий характерен для горных районов Восточной Африки, где основное разнообразие приходится на горнолесные виды [8].

\section{Литература}

1. Андрианов Б. В., Горунг М.Б., Громыко А.А., Кулик С. Ф., Макаров А.А., Старушенко Г. Б., Чижов Н. Н. Страны и народы. Восточная и Южная Африка. Москва, Мысль, 1981. 269 с.

2. Largen M., Spawls S. The amphibians and reptiles of Ethiopia and Eritrea. Frankfurt am Main, Chimaira, 2010.693 p.

3. Rodgers W. A., Owen C. F., Homewood K. M. Biogeography of East African forest mammals // Journal of Biogeography, 1982. Vol. 9. P. 41-54.

4. Freilich X., Tollis M., Boissinot S. Hiding in the highlands: evolution of a frog species complex of the genus Ptychadena in the Ethiopian highlands // Molecular Phylogenetics and Evolution. 2014. Vol.71. P. 157-169.

5. Schiøtz A. Treefrogs of Africa. Frankfurt am Main, Chimaira, 1999. 350 p.

6. Largen M. J. Catalogue of the amphibans of Ethiopia, including a key for their identification // Tropical Zoology. 2001. Vol. 14. P. 307-402.

7. [Anonymous]. Wildlife species list in Bonga. $4 \mathrm{p}$.

8. Poynton J. C., Loader S. P., Sherratt E., Clarke B. T. Amphibian diversity in East African biodiversity hotspots: altitudinal and latitudinal patterns // Biodiversity Conservation. 2007. Vol. 16. P. 1103-1118.

Для цитирования: Мильто К.Д., Пестов М.В., Киршей Т. Предварительные данные по батрахофауне Кафского биосферного заповедника // Вестник Санкт-Петербургского университета. Серия 3. Биология. 2016. Вып. 3. С. 100-106. DOI: 10.21638/11701/spbu03.2016.317

\section{References}

1. Andrianov B.V., Gorung M.B., Gromyko A.A., Kulik S.F., Makarov A.A., Starushenko G.B., Chizhov N. N. Strany i narody. Vostochnaia i Iuzhnaia Afrika [Counties and nations. Eastern and Southern Africa]. Moscow, Mysl' Publ., 1981. 269 p. (In Russian)

2. Largen M., Spawls S. The amphibians and reptiles of Ethiopia and Eritrea. Frankfurt am Main, Chimaira, 2010. 693 p.

3. Rodgers W. A., Owen C. F., Homewood K. M. Biogeography of East African forest mammals. Journal of Biogeography, 1982, vol.9, pp. 41-54. 
4. Freilich X., Tollis M., Boissinot S. Hiding in the highlands: evolution of a frog species complex of the genus Ptychadena in the Ethiopian highlands. Molecular Phylogenetics and Evolution, 2014, vol.71, pp. 157169.

5. Schiøtz A. Treefrogs of Africa. Frankfurt am Main, Chimaira, 1999. $350 \mathrm{p}$.

6. Largen M. J. Catalogue of the amphibans of Ethiopia, including a key for their identification. Tropical Zoology, 2001, vol. 14, pp. 307-402.

7. [Anonymous]. Wildlife species list in Bonga. $4 \mathrm{p}$.

8. Poynton J.C., Loader S. P., Sherratt E., Clarke B. T. Amphibian diversity in East African biodiversity hotspots: altitudinal and latitudinal patterns. Biodiversity Conservation, 2007, vol. 16, pp. 1103-1118.

For citation: Milto K.D., Pestov M.V., Kirschey T. Preliminary data on the batrachofauna of the Kaffa biosphere reserve. Vestnik of Saint Petersburg University. Series 3. Biology, 2016, issue 3, pp. 100-106. DOI: $10.21638 / 11701 /$ spbu03.2016.317

Статья поступила в редакцию 6 февраля 2016 г., принята 30 апреля 2016 г.

Сведения об авторах:

Мильто Константин Дмитриевич - кандидат биологических наук, научный сотрудник

Пестов Марк Валентинович - кандидат биологических наук, консультант

Киршей Том - референт по международным вопросам охраны климата и биоразнообразия

Milto Konstantin D. - PhD, researcher

Pestov Mark V. - PhD, consultant

Kirschey Tom - PhD, officer for International climate conservation and biodiversity 